\title{
Case Control Studies in Medical Research
}

\section{Sathian B1,Sreedharan J², Mittal A3 , Chandrasekharan N4, Baboo NS5, Abhilash ES6, Rajesh E7, Dixit SB ${ }^{8}$}

${ }^{1}$ Assistant Professor, Department of Community Medicine, Manipal College of Medical Sciences, Pokhara, Nepal.

${ }^{2}$ Assistant Director (Research Division), Gulf Medical University, Ajman, UAE.

${ }^{3}$ Associate Professor, Department of Biochemistry, Manipal College of Medical Sciences, Pokhara, Nepal.

${ }^{4}$ Assistant Professor, Department of Orthopaedics, Manipal College of Medical Sciences, Pokhara, Nepal.

${ }^{5}$ Professor, Department of Physiology, Manipal College of Medical Sciences, Pokhara, Nepal.

${ }^{6}$ Lecturer, Department of Biological Sciences, Grammar School, UAE.

${ }^{7}$ Assistant Professor, School of Health and Behavioural Sciences, Mahatma Gandhi University, India.

${ }^{8}$ Professor \& Head, Department of Community Medicine, Manipal College of Medical Sciences, Pokhara, Nepal.

\section{Review Article}

\section{Corresponding Author:}

Dr. Brijesh Sathian, Assistant Professor, Department of Community Medicine, Manipal College of Medical Sciences, Pokhara, Nepal.

E-mail: drsathian@gmail.com

\section{Abstract}

Case-control studies can yield important scientific findings with relatively little time, money, and effort compared with other study designs. Investigators implement case-control studies more frequently than any other analytical epidemiological study. Unfortunately, case-control designs also tend to be more susceptible to biases than other comparative studies. Although easier to do, they are also easier to do wrong. A good design should aim to minimise error and bias. All remaining sources of error and bias should be recognised and decisively evaluated. Casecontrol studies that are well designed and carefully done can provide useful and reliable results. Investigators must, however, devote painstaking attention to the selection of control groups and to measurement of exposure information. When the number of cases is small, the ratio of controls to cases can be raised to improve the ability to find important differences. Although no ideal control group exists, readers need to think carefully about how representative the controls are. Poor choice of controls can lead to both wrong results and possible medical harm. Awareness of these key elements should help readers to identify the strengths and weaknesses of a properly reported study.

Keywords: Bias, Effect size, Confounding

\section{Background}

Case-control methodology is probably the most important contribution epidemiology has made to scientific thinking. Epidemiologists use them to study a huge variety of associations. Therefore, case-control study is an important element in medical research but availability of relevant literature in this topic is scanty. On a recent survey a few of them could be located ${ }^{1-13}$. Case-control study is a type of observational analytical epidemiological investigation in which the subjects are selected on the basis of whether they do (cases) or do not (controls) have a particular disease under study. The groups are compared with respect to the proportion having a history of an exposure or characteristic of interest. Case control studies synonyms are Case- 
comparison study, Case-referent study, Retrospective study, Trohoc study, Fishing expedition.

\section{Selection of Cases}

Newly diagnosed cases are preferred. Researcher should be considered incidence at time of diagnosis and Diagnostic criteria.

\section{Methods of Selecting Cases}

1. All incidence cases in defined population over specific time period ${ }^{14}$.

2. All incidence cases seen at certain hospital over specific time period

3. Cases seeking care from office-based physician

4. Patients seen at pre-paid health plan

5. Schools, places of employment, military service

\section{Selection of Controls}

It is the most difficult and most controversial aspect of study design. The control series is intended to provide an estimate of the exposure rate that would be expected to occur in the cases if there was no association between the study disease and exposure. Individuals selected as controls should not only be free of the disease, but should be similar to the cases in regard to the possibility of having past exposure during the time period of risk ${ }^{15-17}$.

\section{Methods of Selecting Controls}

1. Probability sample of population from which cases come. When possible, random samples of people without the disease can serve as controls. Random sampling should provide representative controls, and extrapolation of results to the study group is easily justified. On the other hand, population controls can be inappropriate when cases have not been completely identified in the population or when substantial numbers of potential controls cannot be reached.

2. School rosters, selective service lists, insurance company lists, Neighbors of cases (Neighbourhood control generally are drawn in a specified pattern from the block in which the case lives).

3. Friends, schoolmates, siblings, fellow-workers, Relatives (Relatives share many traits with cases. When genetic factors are deemed to be confounding, relatives have been used to control for this bias).

4. Persons seeking medical care at the same institution as cases for condition not related to cases disease.

\section{Ascertainment of Exposure}

Ascertainment of Exposure can be done by Personal interviews, Existing records, Physical measurements and lab tests.

\section{Exposure}

Exposures we can classify as Yes / No, Intensity and Length Nepal Journal of Epidemiology 2011;1(3): 77-80 of exposure. For example, in the case of smoking and cancer association study, exposure Smoking has two outcomes Yes/No.

\section{Measure of Effect}

Odds ratio is the Ratio of odds in favor of exposure among cases to odds in favor of exposure among controls ${ }^{18}$. Odds in favor of exposure among cases is ( $\mathrm{a} / \mathrm{c}$ ). Odds in favor of exposure among controls is $(b / d)$. Odds ratio $=$ ratio of 2 odds $=(\mathrm{a} / \mathrm{c}) /(\mathrm{b} / \mathrm{d})=\mathrm{ad} / \mathrm{bc}$.

\section{Bias}

Bias is Systematic (non random) error in a design or conduct of a study and that results in mistaken conclusions regarding the relationship between the exposure and the outcome. Types of Bias are Selection Bias, Information Bias, and Confounding ${ }^{19}$.

\section{Selection Bias}

Selection bias occurs when an investigator inadvertently assigns subjects to comparison groups such that they differ with respect to extraneous factors. Distortions that arise from Procedures used to select subjects, Factors that influence study participation and Systematic error in identifying / selecting subjects. In other words, If the probability of a case being selected into the study is influenced by exposure status of the individual, the study result will be biased. It is better to use incident cases in designing a case control studies rather than prevalent cases. Types of Selection Bias are Berkson Bias, Neyman Bias, Detection, Non-response Bias ${ }^{19}$.

\section{Berkson Bias (admission-rate bias)}

It results from differential rates of hospital admission for cases and controls. Knowledge of the exposure of interest might lead to an increased rate of admission to hospital ${ }^{20}$.

\section{Neyman Bias (incidence-prevalence bias)}

It arises when a gap in time occurs between exposure and selection of study participants. It crops up in studies of diseases that are quickly fatal, transient, or subclinical. It creates a case group not representative of cases in the community.

\section{Detection (unmasking)}

It is an exposure that might lead to a search for an outcome, as well as the outcome itself ${ }^{21}$.

\section{Non-response Bias}

It is another source of selection bias derives from patient or control refusal or non-response to inquiries requesting participation in a study. A refusal may be prompted by a temporary inconvenience in a person's schedule, by a particularly frustrating day with an unusual number of aggravations, or by some subliminal distaste for the tone or 
demeanor of the interviewer making the initial contact.

\section{Information Bias}

Information bias is also known as observation, classification, or measurement bias, resulting from incorrect determination of exposure or outcome, or both. In a casecontrol study, information about exposure should be gathered in the same way for cases and controls. Cases can remember past history of exposure better than healthy controls. Types of Information Bias are Recall Bias and Diagnostic Suspicion Bias.

\section{Recall Bias}

Cases tend to search their memories to identify what might have caused their disease; healthy controls have no such motivation. Occurrence of any disease stimulates its members to provide information associated with disease. Thus information may depend on whether the control was a diseased or non diseased control. Disease itself may cause loss of memory and confusion.

\section{Diagnostic Suspicion Bias}

It implies that knowledge of a putative cause of disease might launch a more intensive search for the disease among those exposed. e.g. If there are more frequent medical examinations, then there will be an increased chance of detecting uterine cancer.

\section{Controlling Bias}

$\begin{array}{cl}\checkmark & \text { Choice of study population } \\ \checkmark & \text { Construction of valid questionnaires } \\ \checkmark & \text { Closed ended questionnaire } \\ \checkmark & \text { Blinding/ Masking } \\ \checkmark & \text { Standard Training } \\ \checkmark & \text { Written Protocols } \\ \checkmark & \text { Multiple sources of information }\end{array}$

\section{Confounding}

A third factor which is related to both exposure and outcome. In any epidemiological study if one finds an association between two variables one need to bear in mind the possibility of being confounded by a third variable. A confounder is independent risk factors which also happen to be associated with the exposure factor under study. A case control study on the association between alcohol intake and myocardial infarction can thus be confounded by smoking. Confounding can be avoided by matching cases and controls for the confounder. Case-control studies need to address confounding bias ${ }^{22,23}$.

\section{Methods to reduce Confounding}

In Design part, you should give emphasis to Randomization, Restriction and Matching apart from these in analysis part on stratified analysis and Multivariate analysis.

\section{Strengths}

1. It can examine multiple etiologic factors for a single disease. (e.g. cardiovascular diseases).

2. It is optimal for the study of rare disease (e.g. leukaemia in adolescents).

3. It is particularly well-suited to the evaluation of diseases with long latent period. (e.g. cancer).

4. It is relatively quick and inexpensive compared with other analytical designs.

\section{Limitations}

1. It cannot directly compute incidence rates of disease in exposed and non-exposed individuals, unless study is population based.

2. In some situations, the temporal relationship between exposure and disease may be difficult to establish.

3. It is particularly prone to bias compared with other analytical designs, in particular selection and recall bias.

4. It is difficult to assemble a representative case group and control group.

\section{Conclusion}

Case-control studies that are well designed and carefully done can provide useful and reliable results ${ }^{24-27}$. Investigators must, however, devote scrupulous attention to the selection of control groups and to measurement of exposure information. Awareness of these key elements should help readers to identify the strengths and weaknesses of a properly reported study. Accurate and thorough description of methods by investigators will result in reader confidence in their results.

\section{References}

1. Avidan B, Sonnenberg A, Schnell TG, Sontag SJ. Risk factors for erosive reflux esophagitis: a case-control study. Am J Gastroenterol 2001; 96: 41-46.

2. Silverman DT. Risk factors for pancreatic cancer: a casecontrol study based on direct interviews. Teratog Carcinog Mutagen 2001; 21: 7-25.

3. Strom BL, Reidenberg MM, West $S$, Snyder ES, Freundlich B, Stolley PD. Shingles, allergies, family medical history, oral contraceptives, and other potential risk factors for systemic lupus erythematosus. Am J Epidemiol 1994; 140: 632-42.

4. Cheng KK, Day NE, Duffy SW, Lam TH, Fok M, Wong J. Pickled vegetables in the aetiology of oesophageal cancer in Hong Kong Chinese. Lancet 1992; 339: 131418.

5. Friedman GD, Hiatt RA, Quesenberry CP, Selby JV. Casecontrol study of screening for prostatic cancer by digital rectal examinations. Lancet 1991; 337: 1526-29.

6. Cramer DW, Harlow BL, Titus-Ernstoff L, Bohlke K, Welch WR, Greenberg ER. Over-the-counter analgesics and risk of ovarian cancer. Lancet 1998; 351: 104-07.

7. Abdel-Salam G, Czeizel AE. A case-control etiologic 
study of microcephaly. Epidemiology 2000; 11: 571-75.

8. Slattery ML, Edwards SL, Ma KN, Friedman GD. Colon cancer screening, lifestyle, and risk of colon cancer. Cancer Causes Control 2000; 11: 555-63.

9. Sackett DL. Bias in analytic research. J Chronic Dis 1979; 32: 51-63.

10. Wacholder S, McLaughlin JK, Silverman DT, Mandel JS. Selection of controls in case-control studies, I: principles. Am J Epidemiol 1992; 135: 1019-28.

11. Perillo MG. Choice of controls in case-control studies. J Manipulative PhysiolTher 1993; 16: 578-85.

12. Wacholder S, Silverman DT, McLaughlin JK, Mandel JS. Selection of controls in case-control studies, II: types of controls. Am J Epidemiol 1992; 135: 1029-41.

13. Ibrahim MA, Spitzer WO. The case control study: the problem and the prospect. J Chronic Dis 1979; 32: 13944.

14. Rothman KJ. Modern epidemiology. Boston: Little, Brown and Company, 1986.

15. Schlesselman J. Case-control studies: design, conduct, analysis. New York: OxfordUniversity Press, 1982.

16. MossAR, Osmond D, Bacchetti P, Chermann JC, BarreSinoussi F, Carlson J. Risk factors for AIDS and HIV seropositivity in homosexual men. Am J Epidemiol 1987; 125: 1035-47.

17. Stadel BV, Rubin GL, Webster LA, Schlesselman JJ, Wingo PA. Oral contraceptives and breast cancer in young women. Lancet 1985; 2: 970-73.

18. Sackett DL, Deeks JJ, Altman DG. Down with odds ratios! Evidence-Based Med 1996;1:164-6.

19. Feinstein AR. Clinical epidemiology: the architecture of clinical research. Philadelphia: WB Saunders Company, 1985.

20. Kronmal RA, Whitney CW, Mumford SD. The intrauterine device and pelvic inflammatory disease: the Women's Health Study reanalyzed. J Clin Epidemiol 1991; 44: 109-22.

21. Feinstein AR, Horwitz RI. Oestrogen treatment and endometrial carcinoma. BMJ 1977; 2: 766-67.

22. Abramson JH. Making sense of data. New York: OxfordUniversity Press, 1988.

23. Hulley SB, Cummings SR, Browner WS, Grady D, Hearst $N$, Newman RB, eds. Designing clinical research: an epidemiologic approach, 2nd edn. Baltimore: Lippincott Williams and Wilkins, 2001.

24. Mittal A, Sathian B, Kumar A, Chandrasekharan N, Sunka A. Diabetes mellitus as a Potential Risk Factor for Renal Disease among Nepalese: A Hospital Based Case Control Study. Nepal Journal of Epidemiology 2010;1 (1):22-5.

25. Mittal A, Sathian B, Chandrasekharan N, Lekhi A, Rahib R, Dwedi S. Hepatic Steatosis and Diabetes Mellitus: Risk Factors, Pathophysiology and with its Clinical Implications: A Hospital Based Case Control Study in Western Region of Nepal. Nepal Journal of Epidemiology 2011;1 (2): 51-6.

26. Mittal A, Sathian B, Chandrasekharan N, Lekhi A, Yadav

Nepal Journal of Epidemiology 2011;1(3): 77-80

Copyright (C) 2011 INEA

Published online by NepJOL-INASP

www.nepjol.info/index.php/NIE
KS. Role of Hypercholesterolemia in Prostate Cancer Case Control Study from Manipal Teaching Hospital Pokhara, Nepal. Asian Pacific J Cancer Prev, 12, 1981-3.

27. Mittal A, Sathian B, Kumar A, Chandrasekharan N, Farooqui MS, Singh S, Yadav K. Hyperuricemia as an Additional Risk Factor for Coronary Artery Disease: A Hospital Based Case Control Study in Western Region of Nepal. Nepal Journal of Epidemiology 2011;1(3): 81-5. 